\title{
Retropharyngeal Abscess in a Four Month Old Female Infant-Case Report
}

\section{Matej Katavić ${ }^{\star}$, Iva Mihatov Štefanović ${ }^{2}$, Renata Vrsalović ${ }^{3}$, Milana Zlatić-Glogoški ${ }^{4}$, Goran Tešović ${ }^{5}$ and Tomislav}

\section{Baudoin ${ }^{6}$}

${ }^{1}$ Pediatric Resident, Pediatric Department in University Hospital Centre Sestre milosrdnice, Vinogradska cesta 29, Zagreb, Croatia

${ }^{2}$ Respiratory Section of Pediatric Department in University Hospital Centre Sestre milosrdnice, School of dental medicine, University of Zagreb

Vinogradska cesta 29, Zagreb, Croatia

${ }^{3}$ Respiratory Section of Pediatric Department in University Hospital Centre Sestre milosrdnice, Vinogradska cesta 29, Zagreb, Croatia

${ }^{4}$ Department of Anaesthesiology, Intensive Medicine and Pain Therapy, University Hospital Centre Sestre milosrdnice, Vinogradska c. 29, Zagreb, Croatia

${ }^{5}$ Pediatric Infectious Disease Institute of Infectious Diseases and Tropical Medicine University Clinical Hospital, Zagreb School of medicine, Mirogojska cesta 8, Zagreb, Croatia

${ }^{6}$ Department of Otorhinolarygology and Head and Neck Surgery, University Hospital Centre Sestre milosrdnice, Zagreb School of medicine, Vinogradska cesta 29, Zagreb, Croatia

\begin{abstract}
Retropharyngeal abscess is acute suppurative infection of the retropharyngeal space. Most commonly it occurs in children younger than four years of age having history of streptoccocal pharyngitis. Clinical presentation similar to epiglottitis or foreign body aspiration makes distinguishing issues so the diagnosis of retropharyngeal abscess can initially be missled. Here we are illustrating four month old female infant with incipient presentation that clinically resembles epiglottitis. After the initial management in the intensive care unit clinical work-up was continued with multidysciplinary collaboration and the diagnosis of retropharyngeal abscess was given, treated both surgically and conservatively. Postoperative intensive care was then continued with subsequent clinical and biochemical improvement. This case demonstrates the need for broad thinking when dealing with affebrile child being respiratory distressed and during diagnostic work-up of a patient having fever of unknown origin.
\end{abstract}

\section{Introduction}

Retropharyngeal abscess is suppurative infection located in retropharyngeal space between the pharynx and the cervical vertebrae, which can be extending through upper parts of mediastinum. It most commonly occurs in children younger than four years of age having medical history of streptococcal pharyngitis, rarely as a complication of recent trauma, odontogenic infection or extension of vertebral osteomyelitis.

Most frequently causative agents are $\mathrm{S}$. aureus and group $\mathrm{A}$ $\beta$-haemolytic streptococcus (GABHS, S. pyogenes), followed by anaerobic bacteria Fusobacterium and Bacteroides. Also, $\mathrm{H}$. Influenzae, Klebsiella sp, Mycobacterium tuberculosis and $\mathrm{M}$. avium - intracellulare can be found [1-8]. The patient is frequently febrile, appears toxic, inapetent, irritable, having respiratory distress. Diagnosis can almost exclusively be given with comprehensive examination and completed with radiographic visualisation of expended retropharyngeal space and presence of air in prevertebral soft tissue. Loss of physiological cervical lordosis can also be seen. Computed tomography and/or magnetic resonance imaging is/are of great diagnostic value to objectify the degree of the disease $[1-5,14,17$ $19,21]$.

With the cooperation of ENT specialist and pediatrician/pediatric infectious disease specialist, treatment consists of a combination of abscess incision and parenteral administration of III generation cephalosporins, usually ceftriaxone. Clindamycin in empirical therapy is also indicated for frequent co-infection of anaerobes. Management in PICU is mandatory due to high risk of complications $[1-5,7,9]$.

\section{Case Report}

BY, female infant, initially presented at the age of 4.5 months. Born from healthy parents in uneventful pregnancy, delivered in time. Her birth weight was $3100 \mathrm{~g}$, birth length $49 \mathrm{~cm}$, she was released from the hospital after three days. She received BCG vaccine in the maternity ward, but in later period wasn't vaccinated at all. She is solely breastfed on demand.

In the neonatal period (August 2016) the girl was hospitalized in our Department due to staphylococcal skin infection witch was treated with local and parenteral therapy with good clinical outcome. In the remaining period she was healthy.

Illness begins two weeks before the admission to the Pediatric Department. The child initally presented with symptoms of afebrile upper respiratory tract infection, clinically resembling viral etiology, which was confirmed by laboratory studies. ENT specialist was consulted, his findings were within normal limits. The day before the admission she lost her appetite, reduced oral intake, having plentiful, thick, tough mucous present in oropharynx with coryza and difficulties breathing. On the day of admission she refused meals and was tachycardic, dyspnoic with shortness of breath, audible inspiratory stridor and needed frequent aspiration of the secretions. Initial laboratory studies revealed - WBC (white blood cells) $24 \times 10^{9} / \mathrm{L}$, segmented PMN (polymorphonuclear) 66, bands

"Corresponding Author: Matej Katavić, Pediatric Department in University Hospital Centre Sestre milosrdnice, Vinogradska cesta 29, Zagreb, Croatia: E-mail: katavicmatej@gmail.com

Citation: Katavić M, Štefanović IM, Vrsalović R, Zlatić-Glogoški M, Tešović G (2016) Retropharyngeal Abscess in a Four Month Old Female Infant-Case Report. Int J Pediatr Neonat Care 2: 121. doi: https://doi.org/10.15344/24552364/2016/121

Copyright: () 2016 Abdel Aziz et al. This is an open-access article distributed under the terms of the Creative Commons Attribution License, which permits unrestricted use, distribution, and reproduction in any medium, provided the original author and source are credited. 
Citation: Katavić M, Štefanović IM, Vrsalović R, Zlatić-Glogoški M, Tešović G (2016) Retropharyngeal Abscess in a Four Month Old Female Infant-Case Report. Int J Pediatr Neonat Care 2: 121. doi: https://doi.org/10.15344/2455-2364/2016/121

Page 2 of 4

6, lymphocytes 17 , monocytes $10 \%$, CRP (C-reactive protein) 52 $\mathrm{mg} / \mathrm{L}, \mathrm{RBC}$ (red blood cells) $4.6 \times 10^{12} / \mathrm{L}, \mathrm{Hb}$ (haemoglobin) $100 \mathrm{~g} / \mathrm{L}$, HCT (hematocrit) 0.332 , platelets $515 \times 10^{9} / 1$. Other laboratory studies were in referent values for age. Several hours after the reception child's general condition subsequently worsened, ENT specialist was consulted giving the initial clinical diagnosis of epiglottitis. Threatening respiratory failure was consequently the main indication for the child to be relocated to the Pediatric Intensive Care Unit. In that time there was no indication for further radiological assessment. In the PICU double empirical antimicrobial therapy with ceftriaxone and azithromycin was carried out with good biochemical response. She received racemic epinephrine, albuterol, fluticasone propionate and dexamethasone inhalations. Nasogastric tube was inserted due to the presence of copious secretions and inability of oral feeding. Microbiological swabs from eyes isolated $S$. pneumoniae and $S$. pyogenes, and nasopharyngeal swab isolated $S$. pneumoniae and $H$. influenzae.

After three-night stay in the ICU, her care and treatment were continued on the Respiratory ward. Upon receipt laboratory studies showed following values - WBC 12.7, segmented PMN 29, bands 0, lymphocytes 53, monocytes 15\%, CRP $6.5 \mathrm{mg} / \mathrm{L}$, ESR (erythrocyte sedimentation rate) $40 \mathrm{~mm} / 3.6 \mathrm{ks}, \mathrm{RBC}, \mathrm{Hb}, \mathrm{HCT}$ and other biochemical findings neat value for age. To single out the finding of immunoglobulin (Ig) G $19.20 \mathrm{~g} / \mathrm{L}$ (IgA 0.81, IgM $1.62 \mathrm{~g} / \mathrm{L}$ ). Peristent refusal of food with inspiratory stridor and overflowing secretions were main reason for extension of diagnostic work-up. Levels of alpha-1-AT (antitrypsin) were within normal limits, chloride sweat test was unsuccesful due to techical reasons.

On the fifth day of admittance ENT specialist was consulted again due to prolonged inability of oral intake, dysphagia, drooling and disturbing weight loss. Oropharyngoscopy and fiber endoscopy were performed enabling inspection of glottis which revealed bulging of the posterior pharyngeal wall and obstructed piriform sinuses. Epiglotis resembled normal, so diagnosis of epiglottitis was ruled out and retrophayngeal abscess was suspected for the first time. Emergency MRI study of the neck was subsequently performed which showed retropharyngeal abscess having dimensions $20 \times 17 \times 33 \mathrm{~mm}$ (Figure 1). On the same day emergency surgery including drainage of the retropharyngeal space was performed which resulted in abundant pus evacuation (Figure 2 and Figure 3.) Postextubation period in the OR was complicated due to oedema of both the aryepiglottic folds and the epiglotis with a substantial decrease in oxygen saturation and consequently bradycardia. The child was re-intubated and again transferred to the Pediatric Intensive Care. 24 hours later she was extubated with no respiratory problems. Laboratory findings during her stay were: WBC 19.6, segm PMN 78\%, Ly 19.6, Mo 3.5, CRP $10.5 \ldots 21 \ldots 10.7 \mathrm{mg} / \mathrm{L}$, ESR $80 \ldots 50 \mathrm{~mm} / 3.6 \mathrm{ks}$, total proteins $70 \mathrm{~g} / \mathrm{l}$, albumin/globulins 17.01, albumin 54.9, alpha-1-globulins 3.5, alpha-2 globulins 11.3, beta-globulins 8.4, gammaglobulins $22.9 \mathrm{~g} / \mathrm{L}$ (persistently elevated) with neat values of RBC, Hb, HCT, platelets and other biochemical values and coagulogram. Swab of the intraoperatively taken sample (PCR - polymerase chain reaction) demonstrated Streptococcus mitis, common comensal in oral flora [20]; tracheal aspirate was bacteriologically negative. After the consultation with pediatric infectologist child was treated with both cephazoline and clindamycin and given other symptomatic therapy. After both surgical and antibiotic therapy prompt recovery and improvement of the clinical status and laboratory findings were witnessed. At this time due to good clinical response to therapy, diagnostic work-up of hypergammaglobulinemia wasn't proceeded.
The child was released in good shape, properly tolerating oral intake with good progression on weight.

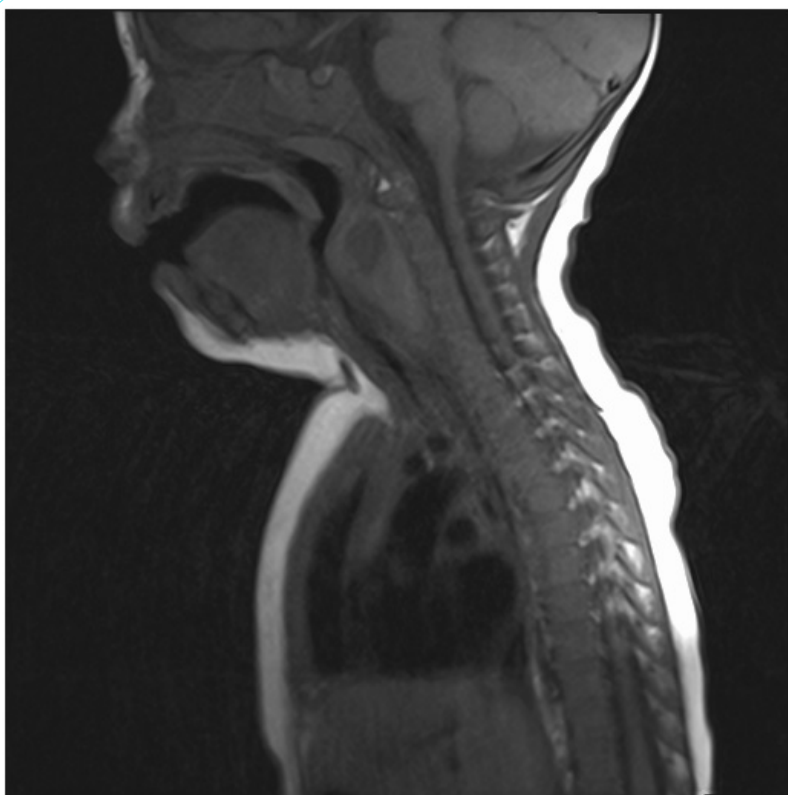

Figure 1: MRI of the neck showing retropharyngeal abscess overhelming larynx and obturated piriformn sinuses.

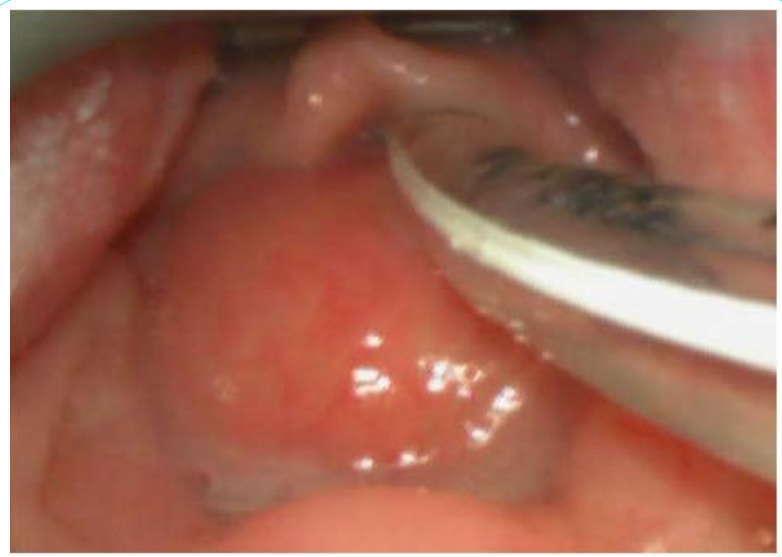

Figure 2: Intraoperative videolaryngoscopy showing bulging of the posterior pharyngeal wall overhanging larynx and obturating piriform sinuses.

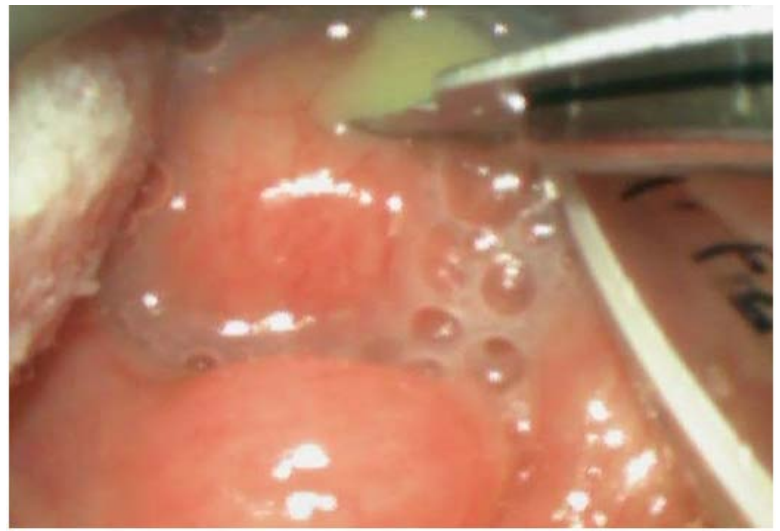

Picture 3: Intraoperative videolaryngoscopy showing pus evacuation after incision. 
Citation: Katavić M, Štefanović IM, Vrsalović R, Zlatić-Glogoški M, Tešović G (2016) Retropharyngeal Abscess in a Four Month Old Female Infant-Case Report. Int J Pediatr Neonat Care 2: 121. doi: https://doi.org/10.15344/2455-2364/2016/121

Page 3 of 4

\section{Discussion}

Infections of upper respiratory tract are common in infants and young children, usually presented with coryza and poor oral intake. Dramatical respiratory distress (suprasternal and subcostal retractions, grunting) with drooling, dysphagia, odynophagia, cervical lymphadenopathy, torticollis [11], unilateral neck and pharyngeal wall swelling is mostly present in children with deep neck infections. In rare cases inspiratory stridor with respiratory distress, cyanosis and long-time refusal of meals should prompt clinician to make an expanded differental diagnostic work-up including epiglottitis, bacterial tracheitis, laryngomalacia, subglotic stenosis, foreign body aspiration, croup or spasmodic croup, lymphoma, hematoma, vertebral osteomyelitis and meningitis (impresses in young age because of the neck stiffness). Both surgical intervention and (dual) antimicrobial therapy are required to resolve and completely treat deep neck infections.

Epiglottitis, although nowadays extremely rare due to continuous vaccination against Haemophilus influenzae type $\mathrm{B}$, should be the main consideration after examining child with severe respiratory distress, having inspiratory stridor with drooling and dysphagia. Child should be kept in upright position, anxiety-provoking interventions such as examination of oral cavity and intravenous line insertion should be avoided. Physician skilled in troublesome airway management should be promptly consulted in case of emergent need for intubation. Therapy is continued in the pediatric intensive care unit. Similar presentation can be seen in foreign body ingestion and/or aspiration children are respiratory distressed with difficulty swallowing. Patients with croup and spasmodic croup have less severe inspiratory stridor and less expressed dysphagia.

Deep neck infection such as parapharyngeal and retropharyngeal abscess impress as epiglottitis, foreign body ingestion incident and severe croup and all have similar treatment access. Nedeed to say, deep neck infections sholud also be managed by surgical intervention $[1-3,5,12,14,18]$ together with parenterally given antibiotics because antimicrobial therapy alone is mainly insufficient for complete resolution. In this case we present a four month old infant who has had a two-week lasting respiratory tract infection and eventually developed deep neck infection at a very early age, without having fever. As far as we found in the literature, there are rare cases of develoment of retropharyngeal abscess at this early age [7,10,11,16,21,22]. Although the first working diagnosis was epiglottitis, both ceftriaxone (as a broad spectrum antibiotic) and azytromicin were introducted as initial therapy because of unvaccinatinated status of the child in order to treat possible pertusis. Fiberendoscopic procedure was actually performed at the initial presentation, but rather interpreted wrongly due to increased amount of saliva in oral cavity with swelling so high suspicious diagnosis of epiglottitis was made. After the five-day course of antimicrobial treatment lack of recovery with persistent drooling and inability of swallowing was noted. Our patient was subsequently examined by the ENT specialist; issues with ingestion of saliva and breast milk were considered to occur due to mechanical obstruction of the pharynx caused by the retropharyngeal abscess (Picture 1,2,3). Unsuccessful antimicrobial therapy alone is main reason why surgical drainage was subsequently performed. In this case it is evident that in selected cases both operative and conservative therapy are imperative in managing patients with deep neck infections [5,12,14,17,18,21]. Radiological evaluation is essential before the surgical intervention in order to objectify the extension of the inflammatory process $[9,17-19]$. Due to high risk of serious complications - septic shock, spontaneous rupture of the abscess with aspiration pneumonia, carotid arthery erosion, suppurative thrombophlebitis of internal jugular veins and mediastinitis, quick and aggressive treatment in the intensive care unit is mandatory [1-5]. Multidysciplinary work-out is desirable and necessary for complete diagnostic and therapeutic management, which was clearly demonstrated in our case report. Main goal of this presentation is to show broad complexity and wide differential diagnostic challenge in affebrile infants who present with respiratory distress. When taken into account, several epidemiological researches and retrospective studies have shown that approximately $30 \%$ pediatric patients do not present with fever or any history of preceeding illness $[4,13,14,21,22]$ Althought our patient didn't have fever, clinician should also consider retropharyngeal abscess in children presenting with unexplained fever [5-7,13].

Altogether, in conclusion, comprehensive diagnostic and therapeutic process should be obligatory in all afebrile infants with clinical picture of severe respiratoy distress and generally in patients with fever of unknown origin with highlight in ruling out the development of retropharyngeal abscess.

\section{Competing Interests}

The authors declare that they have no competing interests.

\section{References}

1. Crain EF, Gershel JC (2010) Clinical Manual of Emergency Pediatrics, V Edition; Cambridge University Press.

2. Hay WW, Levin MJ, Sondheimer JM, Detering RR (2010) Lange Current Diagnosis \& Treatment Pediatrics, 20th Edition, McGraw Hill.

3. Kliegman RM, Stanton B, Geme JS, Schor N, Behrman RE (2011) Nelson Textbook of Pediatrics, 19th Edition, Elsevier Saunders.

4. Römer M, Mäkitie A, Nokso-Koivisto J (2015) University of Helsinki, Helsinki, Finland: Pediatric Deep Neck Infections: a 10-year retrospective single-centre study.

5. Red Book: 2015 Report of the Committee on Infectious Diseases, 30th ed, Kimberlin DW, Brady MT, Jackson MA, Long SS. (Eds), American Academy of Pediatrics, Elk Grove Village, IL 2015.

6. Huang CM, Huang FL, Chien YL, Chen PY (2015) Deep neck infections in children. Journal of Microbiology Immunology and Infection 43: 47-52.

7. Vinograd AM, Zonfrillo MR, Pawel B (2016) Retropharyngeal Abscess and Mediastinitis in a Well-Appearing Infant With Prolonged Fever. Pediatric Emergency Care 33: 43-46.

8. Kelly CP, Isaacman DJ (2002) Group B streptococcal retropharyngeal cellulitis in a young infant: a case report and review of the literature. $J$ Emerg Med 23: 179-182.

9. Kovacić M, Kovacić I, Dželalija B (2015) Descending necrotizing mediastinitis secondary to retropharyngeal abscess. Acta Clinica Croatica 54: 541-546.

10. Garcia Martins RH, Castilho EC, Weber ST, de Oliveira Semenzati G, de Campos LMP (2009) Retropharyngeal abscess and stridor in infants. Rev Bras Otorrinolaringol 75 no.2 São Paulo Mar./Apr. 2009.

11. Mydam J, Thiagarajan $P$ (2009) A nine month old child with retropharyngeal abscess secondary to mastoid abscess presenting as torticollis: a case report. Cases J 2: 6460.

12. Courtney MJ, Mahadevan M, Miteff A (2007) Management of paediatric retropharyngeal infections: non-surgical versus surgical. ANZ J Surg 77: 985-987.

13. Ekanayake R, Haines E, Fiesseler F, Riggs R, Armstrong L, et al. (2011) 430 Most Pediatric Patients With Retropharyngeal Abscess Are Afebrile. Annals of Emergency medicine 58: S324.

14. Craig FW, Schunk JE (2003) Retropharyngeal abscess in children: clinical presentation, utility of imaging, and current management. Pediatrics 111: 1394-1398. 
Citation: Katavić M, Štefanović IM, Vrsalović R, Zlatić-Glogoški M, Tešović G (2016) Retropharyngeal Abscess in a Four Month Old Female Infant-Case Report. Int J Pediatr Neonat Care 2: 121. doi: https://doi.org/10.15344/2455-2364/2016/121

Page 4 of 4

15. Shin JH, Sung SI, Kim JK, Hung JM, Kim ES (2013) Retropharyngeal abscess co-infected with $\mathrm{S}$. aureus and $\mathrm{M}$. tuberculosis after rhinoviral infection in a 1-month-old infant; Korean J Pediatr 56: 86-89.

16. Gathwala G (2010) Retropharyngeal Abscess in the Neonate. Indian Journal of Pediatrics 77.

17. Fédérici S, Silva C, Maréchal C, Laporte E, Sévely A, et al. (2009) Retroand parapharyngeal infections: standardization of their management. Arch Pediatr 16: 1225-1232.

18. Hoffmann C, Pierrot S, Contencin P, Morisseau-Durand MP, Manach $Y$ (2011) Retropharyngeal infections in children. Treatment strategies and outcomes. Int J Pediatr Otorhinolaryngol 75: 1099-1003.

19. Stone ME, Walner DL, Koch BL, Egelhoff JC, Myer CM (1999) Correlation between computed tomography and surgical findings in retropharyngeal inflammatory processes in children. Int J Pediatr Otorhinolaryngo I 49: 121 125.

20. Aas JA, Paster BJ, Stokes LN, Olsen I, Dewhirst FE (2005) Defining the Normal Bacterial Flora of the Oral Cavity. J Clin Microbiol 43: 5721-5732.

21. Acevedo JL (2016): Pediatric Retropharyngeal Abscess; Diseases \& Conditions Medscape.

22. Grisaru-Soen G, Komisar O, Aizenstein O, Soudack M, Schwartz D, et al. (2010) Retropharyngeal and parapharyngeal abscess in childrenepidemiology, clinical features and treatment. Int J Pediatr Otorhinolaryngol 74:1016-20. 